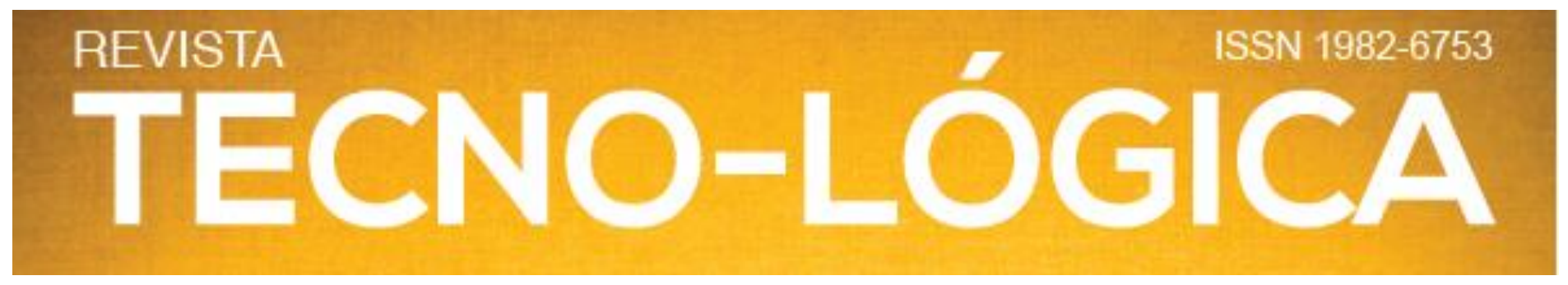

\title{
DIAGNÓSTICO DE ACIDENTES DE TRABALHO COM TRATORES AGRÍCOLAS NO ESTADO DO RIO GRANDE DO SUL, BRASIL
}

\author{
Karen de Oliveira Guinot ${ }^{1}$, José Fernando Schlosser ${ }^{2}$, Daniela Herzog $^{1}{ }^{*}$, Rovian Bertinatto ${ }^{1}$, Natã Balssan Moura ${ }^{1}$ \\ 1 Programa de Pós-Graduação em Engenharia Agrícola, Universidade Federal de Santa Maria, 97105-900, Santa Maria, Brasil. \\ ${ }^{2}$ Departamento de Engenharia Rural, Universidade Federal de Santa Maria, 97105-900, Santa Maria, Brasil.
}

*E-mail:dani_herzog@hotmail.com

Recebido em: 30/03/2021

Aceito em: 02/06/2021

DOI:10.17058/tecnolog.v25i2.16397

\section{RESUMO}

A rápida expansão da mecanização agrícola resultou na geração de um setor despreparado para a prevenção dos acidentes de trabalho, em especial aos que ocorrem com os tratores agrícolas. Com isso, são frequentes as notícias vinculadas nos meios de comunicação sobre acidentes de trabalho envolvendo operadores de tratores no meio rural, ainda que sua quantificação oficial seja difícil, devido à subnotificação desses acidentes. Nesse sentido, o objetivo deste estudo foi realizar um diagnóstico sobre os acidentes de trabalho com tratores agrícolas no estado do Rio Grande do Sul, com base em casos judiciais, a fim de apurar as causas dos acidentes, a atribuição de responsabilidades e a magnitude das consequências representadas pelos danos materiais e pessoais decorrentes desses casos. Através do método dedutivo-sistemático-analítico e da estatística descritiva, foram analisados 60 casos de acidentes de trabalho, no período de 2000 a 2018 e que geraram demandas judiciais. Constatou-se que $96,8 \%$ dos acidentes poderiam ter sido evitados por meio da prevenção, afastando o ato e a condição insegura nas atividades. Em $62 \%$ dos casos o ato inseguro foi a causa dos acidentes, e $14 \%$ foram resultantes da combinação do ato inseguro e da condição insegura. Quanto à responsabilização pela ocorrência do acidente, o empregador foi o responsável direto ou indireto em 59\% dos casos, principalmente pela inobservância das regras de segurança do trabalho, em especial no atendimento das Normas Regulamentadoras NR 12 e NR 31. O óbito do operador ocorreu em 45\% dos acidentes pesquisados, decorrentes do capotamento ou tombamento do trator agrícola. Dessa forma, a análise destes acidentes demonstrou que, em nenhum deles o fato gerador está relacionado a máquina, mas sim a falha humana. Além disso, somente a mudança na postura dos empregadores e trabalhadores poderá resultar na melhoria deste cenário.

Palavras-chave: Máquinas agrícolas. Trabalhadores rurais. Tipos e causas.

\section{Introdução}

Atualmente, verifica-se um crescente compromisso do Estado e seus governos na valorização do trabalhador, visando o reconhecimento da identidade humana em sua essência e minorando a visão da mera fonte de lucro patronal. Essa mudança de paradigma, decorrente de inúmeras pressões sociais, resultou, com o transcorrer das décadas, em um status diferenciado dentro do chamado Estado Social Democrático.

Logo, políticas públicas foram desenvolvidas, sobretudo na forma de normativas, com ênfase na proteção da integridade física do trabalhador e na organização das atividades, e em resposta ao aumento significativo do número de inativos e beneficiários da previdência. Consequentemente, o Estado passa a ser necessariamente interventor-desenvolvimentista, emergindo a necessidade de fazer frente a esta situação, criando e adotando regras mínimas a serem observadas para a preservação da integridade física do "ser humano" que trabalha.

Neste contexto, buscando a máxima cautela e proteção nas atividades profissionais, o agora extinto Ministério do Trabalho e Emprego, por meio da Portaria $\mathrm{n}^{\circ} 3214$, publicou suas Normas Regulamentadoras (NRs) e seus Anexos, que congregam um conjunto amplo e complexo de regras a serem observadas pelos empregadores e empregados, visando a atividade laboral segura.

Destas, estão relacionadas diretamente com o meio rural e principalmente com as máquinas agrícolas, a $\mathrm{NR} \mathrm{n}^{\circ} 31 \mathrm{e}$, mais recentemente, as alterações incluídas na $\mathrm{NR} \mathrm{n}^{\circ} 12$, que trata especificamente de máquinas, e seu anexo exclusivo $\left(n^{\circ} 12\right)$ para 


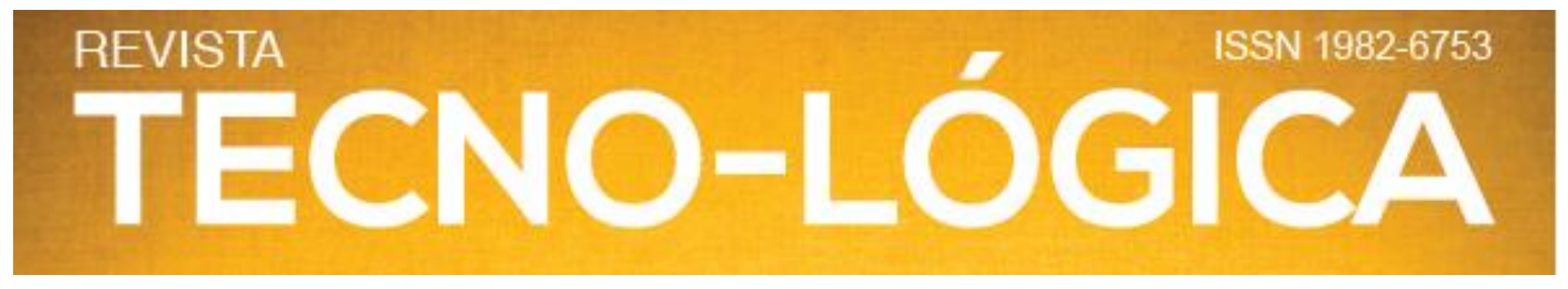

as máquinas agrícolas e florestais. Nesta legislação identifica-se que a base normativa existente não consegue abranger a realidade da vida no campo, das atividades agrícolas e seus agentes, que pela falta de informação ou por mero desinteresse com a saúde humana, desconhecem ou as menosprezam. Logo, o resultado desta cadeia de descumprimento são os graves acidentes com trabalhadores rurais.

O acidente de trabalho é definido no artigo 19 da Lei 8213/91 da legislação previdenciária, como aquele que ocorre pelo exercício do trabalho a serviço da empresa, provocando lesão corporal ou perturbação funcional que cause a morte, a perda ou redução, permanente ou temporária, da capacidade para o trabalho [1]. Outras definições englobam mais claramente as doenças ocupacionais, com relação direta ou indireta ao exercício ou atividade funcional.

O perigo fica por vezes majorado quando se combinam as condições inseguras com os atos inseguros. Ou seja, a natureza da atividade patronal remete à uma condição insegura, a qual é agravada pela realização de um ato inseguro pelo trabalhador [2].

$\mathrm{O}$ ato inseguro normalmente ocorre quando o empregado, muito embora tenha capacitação e conhecimento técnico para a realização da atividade, literalmente ignora as regras e condições básicas de segurança realizando a ação, mesmo ciente de que está correndo risco iminente. No caso, erra quanto à análise pretérita das condições da ação a ser executada, pois o que se depreende da maior parte dos atos inseguros cometidos é que o trabalhador sabe que está fazendo algo indevido, errado, já que se encontra fora dos princípios de prevenção de acidentes, mas mesmo assim corre o risco da produção de um resultado não desejado, porém previsto [3].

Diferentemente do que ocorre no ato inseguro, que depende da ação do trabalhador, na condição insegura o acidente ocorre porque as condições de trabalho, para o exercício da atividade, não são consideradas seguras do ponto de vista da segurança e medicina do trabalho [4]. Esta condição insegura pode estar vinculada à ausência de manutenção e controle de máquinas, ao ambiente de trabalho em si e utilização indevida de equipamentos (fora dos locais apropriados), ou seja, se camufla de várias formas e modalidades [5].

As estatísticas dos acidentes do trabalho demonstram um cenário desolador nas diferentes regiões do Brasil, como pode-se verificar no Anuário Estatístico da Previdência Social. As duas regiões que congregam o maior número de acidentes de trabalho são o Sudeste, com 53,7\% e a região Sul com 22,5\% [6-8].

No que diz respeito à região Sul, especialmente no estado do Rio Grande do Sul, em 2014 ocorreram 61.556 acidentes noticiados, 53.621 no ano de 2015 e 51.609 em 2016, o que significa uma redução aproximada de $20 \%$ entre 2014 e 2016. De igual forma, houve diminuição do número de reconhecimento de casos de incapacidade permanente do trabalhador para o trabalho, pois houve redução de 1.098 registros no ano de 2014 para 889 em 2016 [6-8].

Desta forma, o objetivo principal deste trabalho é realizar um diagnóstico sobre os acidentes de trabalho com tratores agrícolas no Estado do Rio Grande do Sul, com base em casos judiciais, aproveitando-se de documentos oficiais, como laudos periciais e decisões judiciais, a fim de apurar as causas dos acidentes com tratores, a atribuição de responsabilidades e a magnitude das consequências representadas pelos danos materiais e pessoais decorrentes destes casos.

\section{Metodologia}

A pesquisa foi desenvolvida pelo método dedutivosistemático-analítico, partindo de uma ideia geral dos acidentes de trabalho e seus efeitos, para uma específica, no âmbito dos acidentes de trabalho exclusivamente com tratores agrícolas ocorridos no Rio Grande do Sul entre os anos de 2000 a 2018. Face à transversalidade das áreas do conhecimento envolvidas na pesquisa e o levantamento de dados governamentais importantes, foi utilizado o método analítico. Quanto à técnica de pesquisa adotada, esta teve como base o levantamento bibliográfico, documental, normativo e jurisprudencial que envolve o tema proposto.

A pesquisa geral de acidentes teve como fonte documental as estatísticas oficiais da Previdência Social, com a coleta estatística dos acidentes em dados do Instituto Nacional do Seguro Social, em especial dos acidentes de trabalho ocorridos no âmbito rural, com aporte nos dados dos Anuários de 2015, 2016 e 2017, para análise da evolução dos acidentes de trabalho no Brasil e no estado do Rio Grande do Sul.

Para o estudo particular dos acidentes, foi realizada uma coleta de dados a partir do estudo de casos de processos judiciais envolvendo acidentes de trabalho, iniciando-se com a informação de 300 casos de acidentes de trabalho no meio rural, restringindose para 60 casos de acidentes de trabalho especificamente com tratores agrícolas ocorridos no estado do Rio Grande do Sul no período de 2000 a 2018 e que geraram demandas judiciais com decisões prolatadas pelas Varas do Trabalho do Rio Grande do Sul e acórdãos exarados pelo Tribunal Regional do Trabalho da $4^{\mathrm{a}}$ Região.

Os acidentes foram minuciosamente analisados através da identificação dos dados do processo como o Tribunal, número do processo, Turma prolatora da decisão e data de publicação, além da análise da tipologia do acidente, apuração das causas de sua ocorrência e dos fatores geradores destes (ato inseguro, condição insegura, riscos, falha humana, ausência de informação, capacitação e qualificação dos agentes envolvidos), 


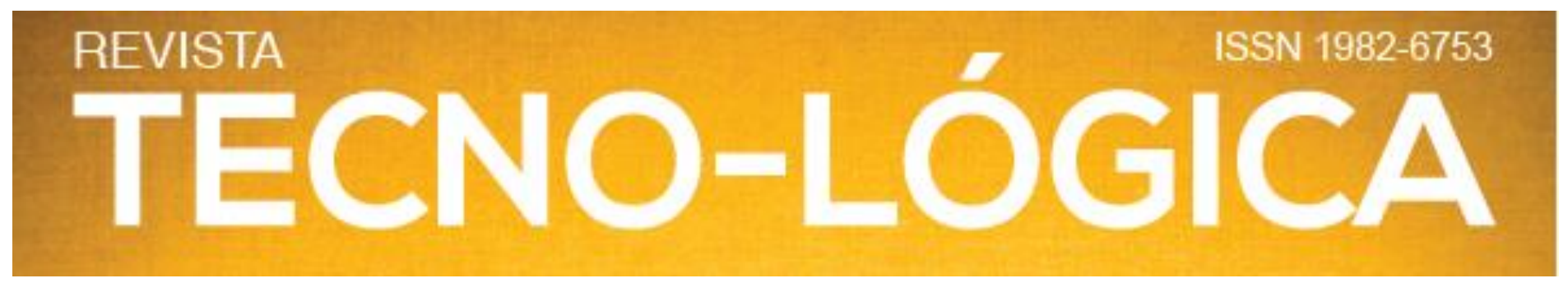

responsabilidade do acidente, extensão dos danos experimentados pela vítima e grau de incapacidade para o trabalho.

Por fim, os dados obtidos neste trabalho foram analisados através da aplicação dos recursos da estatística descritiva. Os dados foram organizados e tabulados e, posteriormente, as frequências absolutas foram transformadas em frequências relativas (\%) e dispostas em gráficos para a apresentação dos resultados.

\section{Resultados e discussões}

Extraindo-se os resultados levantados na amostragem dos fatos geradores dos acidentes, encontrados nas 60 decisões de acidentes de trabalho envolvendo tratores agrícolas, exaradas pela lavra do Tribunal Regional do Trabalho da $4^{\mathrm{a}}$ Região, durante o período compreendido entre os anos de 2000 a 2018, constatou-se que $96,8 \%$ dos casos poderiam ter sido evitados através da prevenção, afastando-se o ato e a condição insegura nas atividades.

Conforme apresentado na figura 1 , em $62 \%$ dos casos analisados $\mathrm{o}$ ato inseguro foi identificado como a causa dos acidentes. $\mathrm{O}$ ato inseguro ocorre normalmente quando $\mathrm{o}$ empregado, embora tenha capacitação e conhecimento técnico para a realização da atividade, ignora as regras e condições básicas de segurança, mesmo ciente de que está correndo um risco iminente. Ademais, $14 \%$ dos casos analisados foram decorrentes da combinação do ato inseguro e da condição insegura.

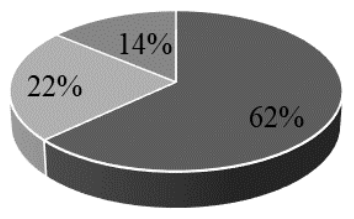

\section{- Ato inseguro \\ - Condição Insegura \\ - Ato inseguro + \\ Condição insegura}

Figura 1 - Causa dos acidentes de trabalho ocorridos especificamente com tratores agrícolas.

Resultados similares foram reportados por Ambrosi e Maggi [9] em um estudo realizado no estado do Paraná, em que identificaram a presença em larga escala do ato inseguro aliado à ocorrência de condição insegura na potencialização dos riscos de acidentes com tratores. Os autores constataram que a principal causa dos acidentes relatados foi a distração/brincadeira, ocorrendo em $50 \%$ dos casos, seguidos pelo excesso de confiança e a ausência dos equipamentos de proteção individual (EPIs), 18\% e $16 \%$ dos casos, respectivamente.

Ao analisar a responsabilização pela ocorrência do acidente constatou-se que o empregador (patronal) foi o responsável, direto ou indireto (culpa in vigilando ou in elegendo), em 59\% dos casos (Figura 2). Isto é, devido a inobservância das regras de segurança do trabalho, em especial no aporte da NR 12 e NR 31 que tratam da prevenção dos acidentes com trabalhadores rurais. A culpa concorrente esteve presente em $21 \%$ dos casos analisados, ou seja, decorreu de uma situação peculiar onde o empregado e o empregador incorrem em grau de culpa na ocorrência do acidente.

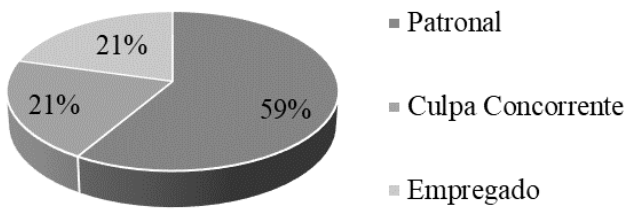

Figura 2 - Responsabilização dos acidentes de trabalho ocorridos especificamente com tratores agrícolas.

No que se refere à gravidade do acidente, $45 \%$ dos casos pesquisados culminaram no óbito do operador, sendo decorrentes do ato inseguro ou da condição insegura a que foram expostos. A figura 3 mostra as principais causas dos acidentes que envolveram o óbito do trabalhador, e observa-se que $33 \%$ dos óbitos ocorreram devido ao capotamento ou tombamento do trator agrícola.

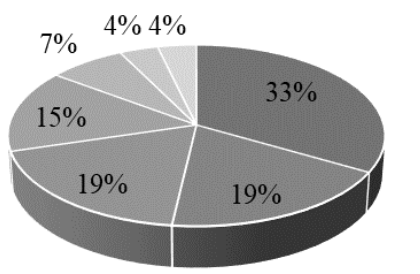

- Capotamento ou tombamento

- Atropelamento

- Queda

- Prensamento

- Eletrocussão

Batida

Colisão

Figura 3 - Causas dos acidentes de trabalho envolvendo o óbito do operador, ocorridos especificamente com tratores agrícolas.

Corroborando com o exposto, Fernandes et al. [10] em estudo envolvendo pesquisa de campo em relação aos acidentes de tratores agrícolas ocorridos nas regiões nordeste, central e leste de Minas Gerais (Brasil), evidenciaram que a maior causa de 


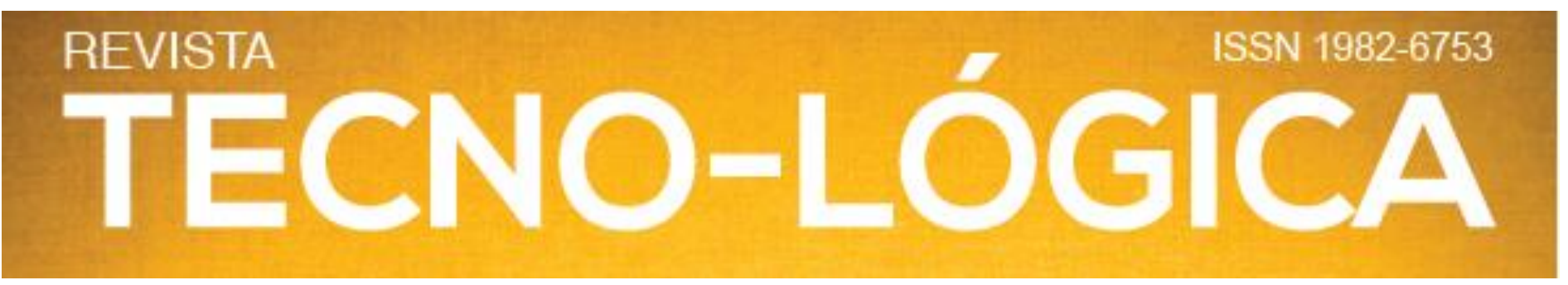

ocorrência de acidentes primeiramente foi o contato com as partes ativas do trator, seguida de situações envolvendo capotamento e tombamento.

Antunes et al. [11], ao analisarem as autopsias de acidentes fatais envolvendo tratores em Portugal, concluíram que 38,6\% dos acidentes foram decorrentes de capotamento, convergindo com os dados encontrados neste trabalho e por outros autores [5, 12-15]. O capotamento ou tombamento de tratores agrícolas é decorrente de diversos fatores, dentre eles: terrenos inclinados ou irregulares; alta velocidade ao mudar de direção; aplicação repentina de tração nas rodas traseiras; transporte de carga não acoplada à barra de tração.

Além disso, conforme Fehlberg et al. [16], a taxa de mortalidade dos acidentes com máquinas agrícolas também é decorrente da própria dificuldade de pronto socorro aos trabalhadores, em função da distância entre as propriedades rurais e os hospitais.

Os 55\% dos casos restantes, onde não houve o óbito do trabalhador, foram analisados quanto às consequências geradas para fins de vida profissional pós-acidente. Constatou-se que a maioria dos acidentes se dividiram entre a ausência de incapacidade para o trabalho (39\%) e a incapacidade permanente para o trabalho (36\%) (Figura 4). Aliás, 91,1\% destes casos foram decorrentes de ato inseguro e condição insegura.

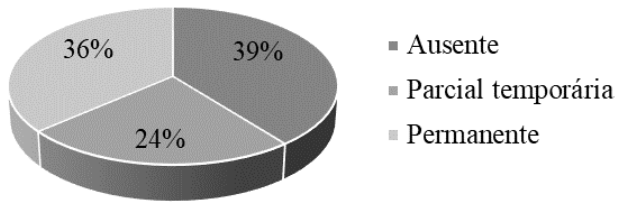

Figura 4 - Extensão dos danos causados pelos acidentes de trabalho, ocorridos especificamente com tratores agrícolas.

Pertinente a questão que envolve o gênero das vítimas de acidentes de trabalho com tratores, 98,4\% ocorreram com trabalhadores do gênero masculino. Este resultado vai ao encontro com os dados reportados por Teixeira e Freitas [17], em estudo realizado no interior do estado de São Paulo, no qual evidenciouse que $90 \%$ dos casos de acidentes também ocorreram com trabalhadores do sexo masculino. Ainda, diversos estudos apontam que a maioria das vítimas envolvidas em acidentes com tratores agrícolas são do sexo masculino com mais de 60 anos [14, $18-21]$.
Segundo estudos realizados por Silva et al. [22], a quantificação das ocorrências dos acidentes no meio rural é difícil devido à subnotificação destes acidentes. Os registros oficiais de acidentes de trabalho são realizados através da Comunicação de Acidente de Trabalho (CAT) porém, ela se restringe aos trabalhadores inseridos no sistema formal de trabalho, sendo excluídos os funcionários públicos civis e militares das três esferas governamentais, os trabalhadores autônomos, domésticos, liberais, dirigentes de micro, pequenas, médias e grandes empresas e trabalhadores informais, resultando na carência de informações a respeito de acidentes de trabalho no Brasil.

\section{Conclusões}

Em nenhum dos casos de acidentes de trabalho envolvendo tratores agrícolas teve como fato gerador do acidente a vinculação com a máquina, em si. O fato gerador é essencialmente a falha humana, de quem opera a máquina ou de quem, embora não opere a máquina, tem o dever de garantir a manutenção e assegurar que esta seja operada de forma segura.

Somente a mudança de postura dos empregadores e dos trabalhadores, em especial no âmago subjetivo do agir, investindo na importância do ato seguro e, consequentemente, na qualificação, capacitação e fiscalização das condições de trabalho, darão conta de mudar este cenário.

\section{Agradecimentos}

O presente trabalho foi realizado com apoio da Coordenação de Aperfeiçoamento de Pessoal de Nível Superior Brasil (CAPES) - Código de Financiamento 001 - e do Conselho Nacional de Desenvolvimento Científico e Tecnológico (CNPq).

\section{DIAGNOSIS OF WORK ACCIDENTS WITH AGRICULTURAL TRACTORS IN THE STATE OF RIO GRANDE DO SUL, BRAZIL}

\begin{abstract}
The increasingly expansion of agricultural mechanization has resulted in the generation of a sector unprepared for the prevention of accidents at work, especially those that occur with agricultural tractors. As a result, news related to work accidents involving tractor operators in rural areas are seen frequently in the media, although their official quantification is difficult due to the underreporting of these accidents. Therefore, the aim of this study was to develop a diagnosis of work accidents
\end{abstract}




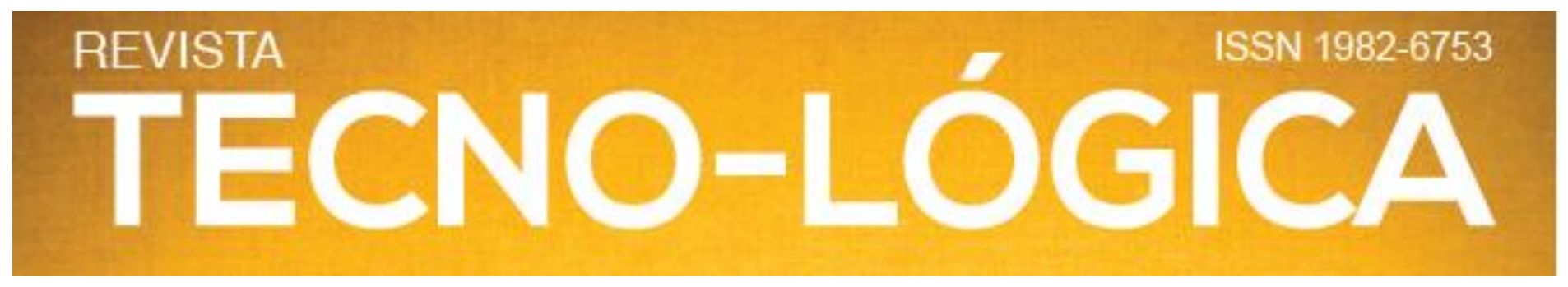

with agricultural tractors in the state of Rio Grande do Sul, based on judicial cases, in order to ascertain the accidents causes, the attribution of responsibilities and the magnitude of consequences represented by the material and personal damages resulting from these cases. Through the deductive-systematic-analytical method and descriptive statistics, 60 cases of work accidents were analyzed, in the period between 2000 and 2018, which generated legal demands. It was found that $96.8 \%$ of accidents could have been avoided through prevention, removing the act and the unsafe condition in the activities. In $62 \%$ of cases, the unsafe act was the cause of accidents, and $14 \%$ resulted from the combination of the unsafe act and the unsafe condition. As for liability for the occurrence of the accident, the employer was directly or indirectly responsible in $59 \%$ of the cases, mainly for non-compliance with the rules of work safety, especially the standards NR 12 and NR 31. The operator's death occurred in $45 \%$ of the accidents analyzed, due to the overturning or fall over of the agricultural tractor. Thus, the analysis of these accidents showed that in none of them the generating event is related to the machine, but rather to human error. Moreover, only the change in the attitude of employers and employees can improve this scenario.

Keywords: Agricultural machinery. Rural workers. Types and causes.

\section{Referências}

[1] BRASIL. Lei No 8213 de 24 de julho de 1991 - Dispõe sobre os Planos de Benefícios da Previdência Social e dá outras providências.

[2] OLIVEIRA, S. G. Indenizações por acidente do trabalho ou doença ocupacional. 3 ed. rev., ampl. e atual. São Paulo: LTr, 2007, 40p.

[3] GONÇALVES, S. P. G.; XAVIER, A. A. P.; KOVALESKI, J. L. A visão da ergonomia sobre os atos inseguros como causadores de acidentes de trabalho. In: Encontro Nacional de Engenharia de Produção, p.2519-2526, 2005, Porto Alegre, RS. Anais. Porto Alegre, RS: ABEPRO, 2005.

[4] PORTAL DA EDUCAÇÃO. Condição insegura no trabalho. São Paulo: Portal da Educação, $2018 . \quad$ Disponível em: $<$ https://siteantigo.portaleducacao.com.br/conteudo/artigos/recursoshumanos/condicao-insegura-no-trabalho/66332> Acesso em: 18 mar. 2021.

[5] SCHLOSSER, J. F.; DEBIASI, H.; PARCIANELLO, G.; RAMBO, L. Caracterização dos acidentes com tratores agrícolas, Ciência Rural, v.32, n.6, p.977-981, 2002.

[6] Anuário da saúde do trabalhador/Departamento Intersindical de Estatística e Estudos Socioeconômicos. São Paulo: DIEESE, 2016. 256p.

[7] Anuário do Sistema Público de Emprego, Trabalho e Renda 2016: Indicadores da Saúde do Trabalhador com base na Rais: livro 7. /Departamento Intersindical de Estatística e Estudos Socioeconômicos. São Paulo: DIEESE, 2017. 130p.

[8] Anuário dos trabalhadores:2018. 13ed./ Departamento Intersindical de Estatística e Estudos Socioeconômicos. São Paulo: DIEESE, 2018. 426p.
[9] AMBROSI, J. N.; MAGGI, M. F. Acidentes de trabalho relacionados às atividades agrícolas. Acta Iguazu, Cascavel, v.2, n.1, p.1-13, 2013.

[10] FERNANDES, H. C.; MADEIRA, N. G.; TEIXEIRA, M. M.; CECON, P. R.; LEITE, D. M. Acidentes com tratores agrícolas: natureza, causa e consequências. Engenharia na Agricultura, Viçosa-MG, v.22, n.4, p.361-371, 2014.

[11] ANTUNES, S. M.; CORDEIRO, C.; TEIXEIRA, H. M. Analysis of fatal accidents with tractors in the Centre of Portugal: Ten years analysis, Forensic Science International, v. 287, p.74-80, 2018.

[12] ERKOL, Z.; BUKEN, B.; HEKIMOGLU, Y.; ERKOL, H.; INCE, H.; ERZENGIN, O. U. Analysis of tractor-related deaths, Journal of Agromedicine, v. 12, n. 2, p.87-97, 2013.

[13] ERLICH, S.; DRISCOLL, T. R.; HARRISON, J. E.; FROMMER, M. S.; LEIGH, J. Work-related road fatalities in Australia, 1982-1984, Scandinavian Journal of Work, Environment \& Health, v.19, n.3, p.162-167, 1993.

[14] HARD, D. L.; MYERS, J. R.; GERBERICH, S. G. Traumatic injuries in agriculture, Journal of Agricultural Safety and Health, v. 8, n. 1, p.51-65, 2002.

[15] KARLSON, T.; NOREN, J. Farm tractor fatalities: the failure of voluntary safety standards, American Public Health Association-AJPH, v.69, n.2, p.146-149, 1979.

[16] FEHLBERG, M. F.; SANTOS, I. S.; TOMASI, E. Acidentes de trabalho na zona rural de Pelotas, Rio Grande do Sul, Brasil: um estudo transversal de base populacional, Cad. Saúde Pública, Rio de Janeiro, v.17, n.6, p.1375-1381, 2001.

[17] TEIXEIRA, M. L. P.; FREITAS, R. M. V. Acidentes do trabalho rural no interior paulista. São Paulo em Perspectiva, v.17, n.2, p.81-90, 2003.

[18] PICKETT, W.; HARTLING, L.; BRISON, R. J.; GUERNSEY, J. R. Fatal work-related farm injuries in Canada, 1991-1995, Canadian Medical Association Journal, v.160, n.13, p.1843-1848, 1999.

[19] ARANA, I.; MANGADO, J.; ARNAL, P.; ARAZURI, S.; ALFARO, J. R.; JARÉN, C. Evaluation of risk factors in fatal accidents in agriculture, Spanish Journal of Agricultural Research, v.8, n.3, 2010.

[20] RORAT, M.; THANNHAUSER, A.; JUREK, T. Analysis of injuries and causes of death in fatal farm-related incidents in Lower Silesia, Poland, Annals of Agricultural and Environmental Medicine, v.22, n.2, p.271-274, 2015.

[21] RAUTIAINEN, R. H.; REYNOLDS, S. J. Mortality and morbidity in agriculture in the United States, Journal of Agricultural Safety and Health, v.8, n.3, p.259-276, 2002.

[22] SILVA, J. R.; FURLANI NETO, V.; SIDOU, N. B. A.; GONÇALVES, E. T.; BACCI, C. Acidentes graves no trabalho rural entre 1994 e 1997 na região centrosul do estado de São Paulo, Brasil, Rev. Inst. Flor., São Paulo, v.131, n.1, p.83-97, 2001 . 